\title{
ERRATUM
}

\section{Drug Monitoring: Bright lights yield drug readout}

Lei Ge \& Jinghua Yu

Nat. Chem. Biol. 10, 490-491 (2014); published online 17 June 2014; corrected after print 17 June 2014

In the version of this article initially published, the text referred to panels a and b within Figure 1, but no panels were present in the image. The error has been corrected in the HTML and PDF versions of the article.

\section{ERRATUM}

\section{Cyclic dinucleotides bind the C-linker of HCN4 to control channel cAMP responsiveness}

Marco Lolicato, Annalisa Bucchi, Cristina Arrigoni, Stefano Zucca, Marco Nardini, Indra Schroeder, Katie Simmons, Marco Aquila, Dario DiFrancesco, Martino Bolognesi, Frank Schwede, Dmitry Kashin, Colin W G Fishwick,

A Peter Johnson, Gerhard Thiel \& Anna Moroni

Nat. Chem. Biol. 10, 457-462 (2014); published online 28 April 2014; corrected after print 16 June 2014

In the version of this article initially published, a data point and one of its two error bars were missing from Figure $3 \mathrm{e}$ in the row depicting mutant F564T. The error has been corrected in the HTML and PDF versions of the article.

\section{CORRIGENDUM}

\section{Dissecting motility signaling through activation of specific Src-effector complexes}

Andrei V Karginov, Denis Tsygankov, Matthew Berginski, Pei-Hsuan Chu, Evan D Trudeau, Jason J Yi, Shawn Gomez, Timothy C Elston \& Klaus M Hahn

Nat. Chem. Biol. 10, 286-290 (2014); published online 9 March 2014; corrected after print 7 April 2014

In the version of this article initially published online, the colors of the purple (SH2 mutant + FAK-FRB) and green (SH2 mutant + p130Cas-FRB) curves in Figure 3d were swapped, leading to a mislabeling of the two experimental results. The error has been corrected for the PDF and HTML versions of this article.

\section{CORRIGENDUM}

\section{Dual kinase-bromodomain inhibitors for rationally designed polypharmacology}

Pietro Ciceri, Susanne Müller, Alison O'Mahony, Oleg Fedorov, Panagis Filippakopoulos, Jeremy P Hunt, Elisabeth A Lasater, Gabriel Pallares, Sarah Picaud, Christopher Wells, Sarah Martin, Lisa M Wodicka, Neil P Shah, Daniel K Treiber \& Stefan Knapp

Nat. Chem. Biol. 10, 305-313 (2014); published online 2 March 2014; corrected after print 4 April 2014

In the version of this paper originally published, funding from the Wellcome Trust to P.F. and S.P. was not acknowledged. The acknowledgments have been corrected in the HTML and PDF versions of the article. 